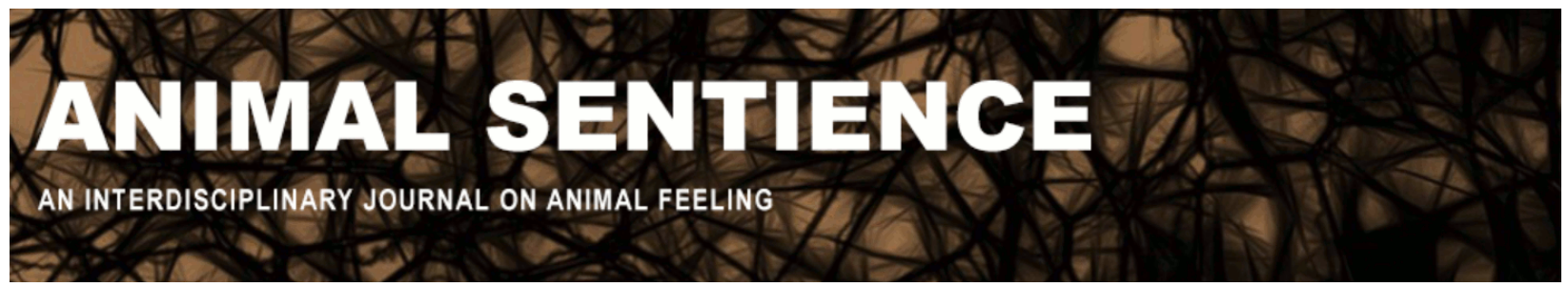

Hart, Paul J.B. (2016) Fighting forms of expression. Animal Sentience 3(9) DOI: $10.51291 / 2377-7478.1040$

Date of submission: $2015-10-12$

Date of acceptance: 2015-12-11

(c) (i)




\title{
Fighting forms of expression
}

Commentary on Key on Fish Pain

\author{
Paul J. B. Hart \\ Neuroscience, Psychology and Behaviour \\ University of Leicester
}

\begin{abstract}
Even though Key (2016) has done a very thorough job of assembling evidence showing that fish are unlikely to have the neurological capacity to be conscious and feel pain, there will still be a significant number of behavioural biologists who want to continue maintaining that fish do have consciousness and suffer from pain. In this commentary the reasons for people resisting the conclusions of the evidence are discussed. The reasons revolve around three aspects of the debate: the overblown respect humans have for the powers of consciousness in our day-to-day behaviour, the often used assumption that the possession of complex behaviour must mean that an animal is conscious, and by the misapplication of words such as 'pain.'
\end{abstract}

Paul J. B. Hart pbh@le.ac.uk is Emeritus Professor of Fish Biology and Fisheries, at University of Leicester. He does fieldwork on the ecology and management of inshore fisheries, especially crab fisheries and individualbased modelling of mechanisms that drive the fishery or the ecology of the stock being exploited. He has also worked extensively on fish foraging behaviour http://www2.le.ac.uk/departments/npb/people/pbh



troduction. What is fascinating about the debate addressed by Key's (2016) target article is that the topic divides scientists into two distinct groups. Key represents those who consider that the important task is to examine the neurological evidence for the existence in fish of consciousness and the ability to feel pain. He has done an excellent job of assembling the evidence to show that it is very unlikely that fish do feel pain, but as the commentaries on his article will no doubt show, there will still be people who remain unconvinced and continue to maintain that fish are conscious and feel pain. I want to understand why this second group remains unconvinced, and my commentary explores potential reasons.

Barriers to rational discussion. I propose that three aspects of human behaviour get in the way of rational discussions of pain in fish. These are the consequences for the discussion about fish pain of the assumption many make that consciousness is more influential than it really is in deciding how humans behave. It is also assumed that complex behaviour has to imply consciousness. Finally, the language used to describe pain and consciousness in humans is misused when applied to non-humans and hampers rational discussion. In what follows I explore the consequences of these three factors.

1. The awe with which we regard our own conscious powers. A little introspection shows that much of our behaviour is accomplished with little participation of conscious processes (Gray 2004, Custers and Aarts 2010, Kahneman 2011). For many motor tasks, such as 
returning a tennis ball, the conscious experience of the event lags behind the action by about one fifth of a second (Gray 2004). Consciousness reviews rather than directs. Evolution has favoured the myth that our lives are directed by conscious decisions. Humphrey (2006) proposes that through this myth we create a sense of self to which events can happen, further giving us the ability to create goals and give life meaning.

For most humans, the myth of conscious control of their lives is so powerful and persuasive that action without it, even in non-humans, seems impossible. If, instead, one takes the view that many of the complex behaviours that we employ are monitored and informed by consciousness but are not directed by it, then we are freer to assess non-human behaviour for what it is.

2. The belief that complex behaviour has to imply consciousness. An important corollary of the belief that consciousness is of over-riding importance to complex human behaviour is that it must be true of animals too. Otherwise one has to acknowledge that unconscious processes can direct complex behaviour.

As a result of their belief that complexity means consciousness, scientists studying animal behaviour are adopting language that assumes that animals have conscious feelings and emotions because they show complex behaviours. For example, Verheijen and Flight (1997) conclude unequivocally that fish have subjective experiences and can suffer. Yue et al (2004) report that rainbow trout (Oncorhynchus mykiss) feel fear when attacked by a simulated predator. In a similar vein, Bateson and Matheson (2007) attribute feelings of pessimism to starlings (Sturnus vulgaris) and, more generally, Wiepkema and Koolhaas (1992) consider that all vertebrates employ emotions to deal with their environment.

The use of the language of feelings and emotions, including pain, is dangerous because of the human meanings that they carry. We need to adopt a more cautious terminology (LeDoux 2015). The modern resurgence of research that considers mental states as legitimate targets of investigation is a reversal of the views of early ethologists. For example, Tinbergen (1951) wrote that "... to ascribe a causal function to something that is not objectively observable [e.g., consciousness or feelings] often leads to false conclusions." Whilst there are ways to explore the mental states of non-humans, as demonstrated by Cheyney and Seyfarth (1990, 2007), many present-day researchers are abandoning the evidence-based approach to the understanding of animal minds and making unjustified assumptions derived from their view that complex behaviour means conscious action.

3. The misuse of language. There are also semantic and philosophical issues when the words 'conscious' and 'pain' are used to speak about non-humans. As humans, we have good reason to believe that others share our own mental experiences (Figure 1). We even have neural processes that mirror the actions of others, thus giving us a good insight into what they are thinking (e.g., Frith and Frith 2006). We also work on the assumption that fellow humans have brains and behaviours that are closely similar to our own; so we are comfortable assuming that others think and feel as we do. As Baron-Cohen (1995, p. 21) has written, "Attributing mental states to complex systems (such as a human being) is by far the easiest way of understanding it." So words such as 'pain,' 'fear,' 'suffering,' and 'consciousness' are words we use to describe and express our own and others' mental 
states. When it comes to non-humans - and this is particularly true of fish - we cannot use the words 'conscious' or 'pain' in the same way.

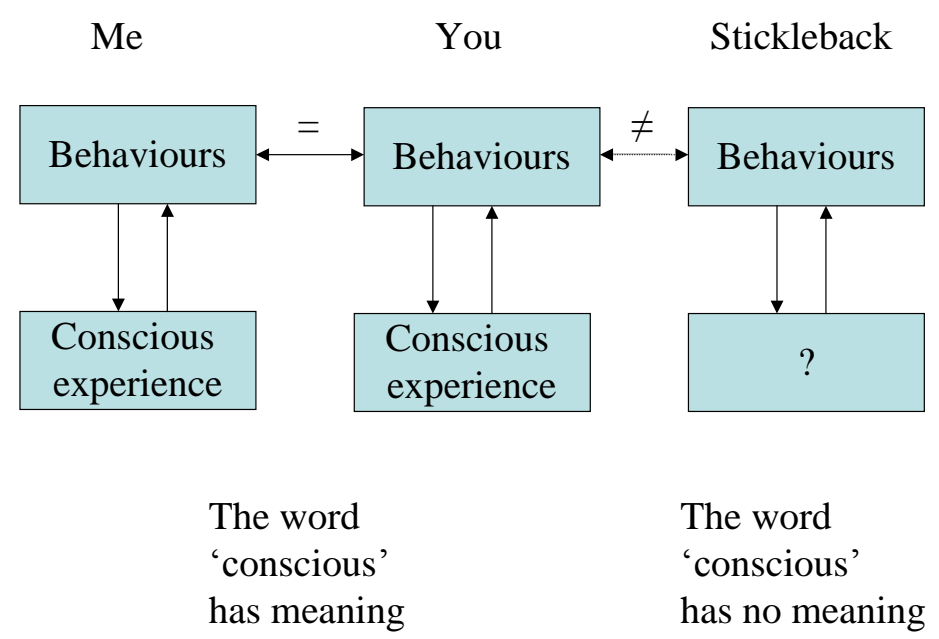

Figure 1. A conceptual modal of the way meaning can or cannot be given to the word 'consciousness' in the human and non-human contexts.

Without a clear view of how a word can be used and what we refer to when we use it, we cannot deal with the world. The way meaning is to be understood has been discussed by many philosophers. In his later philosophy, Wittgenstein (1953) considered that the meaning of words is defined by their use in a process he called a 'language game' whose rules we learn in early life. In particular (paragraph 244), he describes how a child might learn to use the word 'pain' - "A child has hurt himself and he cries; and then adults talk to him and teach him exclamations and, later, sentences. They teach the child new pain-behaviour." In this view of the meaning of words we can only agree on how to use a word if we share a common view of the world (see Figure 1). As we do not share a common view of the world with a fish, can we then use words from human experience to describe the inner experiences of a fish?

Conclusions. This commentary illustrates how the human preoccupation with the conscious part of our behaviour distorts our view of how non-humans behave. Abandoning this preoccupation makes it easier to accept that fish can achieve complex behaviours through automatic processes. Consequentially automatic responses to noxious stimuli do not need the animal to experience pain. In the literature on animal welfare, scientists discussing consciousness, pain and suffering in non-humans use these concepts as if they were well understood. As I have tried to show, in the human context the use of these words is mutually understood, but I have argued that we are not justified in using the same words when talking about non-humans (Dawkins 2012). There is a strong case for a much more rigorous approach to how concepts such as 'pain' and 'fear' are used when referring to non-humans. 


\section{References}

Baron-Cohen, S. (1995) Mindblindness: An essay on autism and theory of mind. Cambridge: MIT Press.

Bateson, M. and Matheson, S. M. (2007) Performance on a categorisation task suggests that removal of environmental enrichment induces 'pessimism' in captive European starlings (Sturnus vulgaris). Animal Welfare, 16, 33-36.

Cheney, D. L. and Seyfarth, R. M. (1990) How monkeys see the world. Chicago: Chicago University Press.

Cheyney, D. L. and Seyfarth, R. M. (2007) Baboon metaphysics. The evolution of a social mind. Chicago: Chicago University Press.

Custers, R. and Aarts, H. (2010) The unconscious will: how the pursuit of goals operates outside of conscious awareness. Science, 329, 47-50.

Dawkins, M. S. (2012) Why animals matter: animal consciousness, animal welfare, and human well-being. Oxford: Oxford University Press.

Frith C. D. and Frith, U. (2006) The neural basis of mentalizing. Neuron, 50, 531-534.

Gray, J. (2004) Consciousness. Creeping up on the hard problem. Oxford: Oxford University Press.

Humphrey, N. (2006) Seeing red: a study in consciousness. Cambridge: Belknap Press of Harvard University Press.

Kahneman, D. (2011) Thinking, fast and slow. London: Penguin Books.

Key, B. (2016) Why fish do not feel pain. Animal Sentience 2016.003.

LeDoux, J. (2015) Anxious. The modern mind in the age of anxiety. London: Oneworld Publications.

Tinbergen, N. (1951) The study of instinct. Oxford: Oxford University Press.

Verheijen, F. J. and Flight, W. F. G. (1997) Decapitation and brining: experimental tests show that after these commercial methods for slaughtering eel Angullla anguilla (L.) death is not instantaneous. Aquaculture Research, 28, 361- 366.

Wiepkema, P. R. and Koolhaas, J. M. (1992) The emotional brain. Animal Welfare, 1, 13-18. Wittgenstein, L. (1953) Philosophical investigations. Oxford: Blackwell Publisher

Yue, S. Moccia, R. D. and Duncan, I. J. H. (2004) Investigating fear in domestic rainbow trout, Oncorhynchus mykiss, using an avoidance learning task. Applied Animal Behaviour Science, 87, 343-354. 